\title{
The Morally Desirable Option for Nuclear Power Production
}

\author{
Behnam Taebi
}

Received: 1 November 2010 /Accepted: 10 April 2011 /Published online: 3 May 2011

C The Author(s) 2011. This article is published with open access at Springerlink.com

\begin{abstract}
This paper reflects on the various possible nuclear power production methods from an ethical perspective. The production and consumption of nuclear power give rise to the problem of intergenerational justice; in other words, we are depleting a nonrenewable resource in the form of uranium while the radiotoxic waste that is generated carries very long-term potential burdens. I argue that the morally desirable option should therefore be to seek to safeguard the interests of future generations. The present generation has at least two duties with regard to posterity: (1) not to jeopardize the safety and security of future generations or impose any harm upon them and (2) to sustain future well-being insofar as that is possible with the available energy resources. These duties are presented as pluralist prima facie duties (or duty-imposing reasons) thus implying that they could well be overruled by morally more compelling duties. If we are unable to fulfill both these prima facie duties simultaneously, it should be particularly the duty not to impose harm on posterity that should be the leading incentive behind nuclear power production. This supports the arguments in favor of the introduction of a new fuel cycle (partitioning and transmutation) that can substantially reduce the waste lifetime and therefore also potential future burdens. However, the further development and application of this scientifically proven but not yet industrialized fuel cycle give rise to additional burdens for contemporaries. This paper examines the extent of the moral stringency of the no harm duty sought for situations in which future interest should guide us in our choosing of a certain technology.
\end{abstract}

Keywords Intergenerational justice $\cdot$ Nuclear power $\cdot$ Fuel cycle $\cdot$ Temporal duty Prima facie duty $\cdot$ Future generations $\cdot$ No harm principle $\cdot$ Vital interests

\footnotetext{
B. Taebi $(\bowtie)$

Department of Philosophy, Delft University of Technology, Jaffalaan 5, 2628 BX Delft, the Netherlands

e-mail: B.Taebi@tudelft.nl

URL: www.ethicsandtechnology.eu/taebi
} 
The recent nuclear accident in Fukushima Daiichi in Japan has again brought the nuclear debate to the forefront of controversy. While Japan is trying to avert further disaster, many nations are reconsidering the future of nuclear power in their region. The many advantages of nuclear power largely ensue from the fact that large amounts of energy can be produced from small amounts of fuel while giving rise to very low greenhouse gas emissions. It is especially in conjunction with the growing worldwide demand for energy and the mounting climate change concerns that nuclear power has increasingly attracted attention in recent years. Another important advantage of nuclear power is that it reduces the reliance that countries have upon fossil fuel for their energy provision. This is why a country like Japan with almost no oil and gas reserves has always drawn heavily on nuclear power; one in every eight of the world's nuclear power plants is currently in Japan.

Obviously, nuclear power has serious disadvantages too, one needs only think of the accident risks - the unfolding disaster in Japan speaks for itself - there are security concerns in relation to the proliferation of nuclear weapons and, indeed, there is the matter of long-lived waste. In this paper, I do not intend to get involved in the general desirability debate. I assert that when carefully reflecting on the desirable energy mix for the future, one needs to reflect on nuclear energy in relation to other energy sources. In so doing, one should first be aware of the distinctive aspects of nuclear technology, such as the problems that long-lived waste poses to future generations. We should furthermore include different technological methods in the production process (or fuel cycles) as these methods deal differently with the distinctive aspects.

In this paper, I introduce the desirable option in relation to nuclear power production, which I shall approach from a moral point of view. In other words, if we intend to continue with nuclear power production, which technology is most morally desirable? The latter will be approached from the perspective of the duties of contemporaries if we are to safeguard the interests of future generations. There are two basic reasons for focusing on the interest of posterity when addressing the desirability issue: (1) in producing nuclear power, we are creating an intergenerational problem; namely, the benefits are predominantly for this generation and the burdens will, in part, be postponed and (2) we are in a temporally beneficiary position to visit costs on our descendants and can therefore easily exploit this position. In Section 1, I shall elaborate on this discussion.

The desirable option is therefore primarily perceived to be that of safeguarding the interests of future generations. It is argued that in choosing the technology for nuclear power production, there are at least two duties that the present generation has, namely, to benefit future people and not to harm them. These duties are presented in Section 2 as pluralist prima facie duties implying, in other words, that they could be overridden by more compelling duties. In this way, moral pluralism enables us to address the conflicts. The extent of the moral stringency of the presented duties is examined in Section 3. That section also questions which of the two duties should be decisive if they cannot be simultaneously complied with. Section 4 briefly reviews the existing and future production methods that would comply with the duties. The application of these technologies shifts the burdens and benefits for different generations, which can potentially be conflicting. Those intergenerational conflicts are then explored in Section 5; that section furthermore 
presents three challenges to the idea of imposing additional burdens on the present generation in order to curtail the harm incurred on future generations. I conclude the paper by presenting the findings in brief.

The assumption underlying the analysis in this paper is that nuclear power deployment will continue. This should not, however, be seen as a normative statement regarding the societal desirability of nuclear power. This assumption is merely made in order to be able to reflect on the different nuclear power production methods in a restricted domain. In the discussion section (Section 5), I will return to this assumption and evaluate whether it paralyzes the analysis.

\section{Nuclear Power Production and Temporal Duties}

There are two reasons why this generation's production of nuclear power creates the problem of intergenerational justice. First of all, if we assume that all generations (ours and those that follow) have access to the same finite resources (uranium) and that we might be able to asymmetrically influence their interest, a "Pure Intergenerational Problem" (PIP), as argued by Gardiner (2003), will emerge, which is in fact an exacerbated form of the prisoner's dilemma extended over generations. He imagines a world consisting of temporally distinct groups that can asymmetrically influence each other; "earlier groups have nothing to gain from the activities or attitudes of later groups." Each generation has access to a diversity of temporally diffuse commodities. Engaging in activity with such goods culminates in modest present benefits and substantial future cost and that in turn poses the problem of justice.

A typical example of the PIP is the general (fossil fuel) energy consumption situation which is characterized by predominantly good immediate effects but deferred bad effects in terms of the anthropogenic greenhouse gas emissions that cause climate change. Intergenerational justice and climate change have received increasing attention in recent years (Page 1999; Shue 1999; Gardiner 2001; Athanasiou and Baer 2002; Shue 2003; Meyer and Roser 2006; Page 2006). The main rationale behind these discussions is that change in a climate system that threatens the interest of future generations raises questions concerning justice and posterity. The same rationale also applies to the production of nuclear power. In the case of fossil fuel combustion, it is the emitting of greenhouse gasses that can trigger long-term climatic change for posterity, while with nuclear power deployment, it is the creation of long-lived radiotoxic waste that could potentially pose safety and security problems to future generations. In addition to the presence of long-lived waste, depleting a nonrenewable resource (uranium) in nuclear power production adds another important intergenerational dimension to the problem.

A further salient feature of this problem is that it could be "perfectly convenient" for the present generation to "exploit its temporal position" and to visit costs on future generations (Gardiner 2006, 408). Let me elaborate on what is meant here by our beneficial temporal position. When discussing future benefits, a typical economic argument is that future generations will be better off than the present generation, all of which should justify treating future benefits differently. This obviously conflicts with the beneficial position of the present generation. What is 
meant by our beneficial position is, however, the plain fact that we live now while they will live in the future. So we are-temporally speaking-in a position to influence their interests, while they cannot influence ours in any way whatsoever. In nuclear power discussions, we can easily pass on the burden of waste to posterity and that makes us susceptible to "the problem of moral corruption" (Gardiner 2006, 408). ${ }^{1}$ This provides us with a moral ground for defending obligations to future generations.

In the remainder of this section, I will explore the way in which we can contemplate justice to posterity in the case of nuclear power. In so doing, I shall follow Brian Barry's (1999) principles concerning the fundamental equality of human beings when it comes to the matter of addressing intergenerational justice. Barry expounds his theory by spelling out the normative aspects of the notion of sustainable development and by commenting that the value of an entity $\mathrm{X}$ as we enjoy it should be sustained into the future so that future generations do not fall below our level of X. He then presents principles for the theorems of fundamental equality, two of which are the principle of responsibility - "[a] bad outcome for which somebody is not responsible provides a prima-facie case for compensation"and the principle of vital interests: "location in space and time do not in themselves affect legitimate claims ... [therefore] the vital interests of people in the future have the same priority as the vital interests of people in the present" (Barry 1999, 97-99).

What is this valuable entity of $\mathrm{X}$ that should be distributed equitably over generations? That is the next question we have to ask ourselves. Barry proposes opportunity as a metric of justice: a requirement of justice is that "the overall range of opportunities open to successor generations should not be narrowed. If some openings are closed off by depletion or rather irreversible damage to the environment, others should be created (if necessary at the cost of some sacrifice) to make up" (Barry 1978, 243). So, while adhering to the guiding principle that we should not narrow the total range of opportunities, I will develop two other principles that will lead to the matter of how this main principle relates to nuclear power generation, the main rationale being that whenever we find ourselves in a position to negatively influence the opportunities open to future generations, we should be careful not to narrow these opportunities.

We should recall the two intergenerational aspects of nuclear power production and how those could affect posterity's equal opportunity. The first intergenerational aspect of nuclear energy-related discussions is the fact that we leave behind radiotoxic waste with tremendously long lifetime periods. If not properly disposed

\footnotetext{
${ }^{1}$ Stephen Gardiner puts forward this argument in the case of climate change where he addresses three main related problems which he refers to as three storms. "These three 'storms' arise in the global, intergenerational and theoretical dimensions, and [...] their interaction helps to exacerbate and obscure a lurking problem of moral corruption" (Gardiner 2006: 399). Even though only two of the three "storms" relate to the problem of nuclear power production and the accompanying waste (i.e., theoretical and intergenerational), I believe that the main rationale of this argument, which is based on our advantageous temporal position to impose harm on future generations, is not undermined.

${ }^{2}$ Other scholars too, such as Arneson (1989), have also defended equality of opportunity as a metrics for justice. Objections could however be made to this currency of justice; see for instance Page's discussion (Page 2006, 54-59) for an overview of the literature available on this ongoing issue. Again, other scholars propose other currencies, for instance capability (Sen 1982). It would be beyond the scope of this work to enter into such discussions here.
} 
of, this waste can influence the safety and security of future generations and therefore also their vital interests. So, the first intergenerational duty I will discuss is one that relates to the safety and security of future generations or to their vital interests. The second intergenerational aspect of nuclear power generation is the fact that by depleting a non-replaceable resource (uranium), we are giving future generations less access to it. If we assume that well-being significantly relies on the availability of energy resources, we are in a position to influence future opportunity for well-being. From the latter, I conclude that we have a moral obligation to ensure the future's opportunity for well-being — or to sustain future well-being - insofar as it can be achieved by the availability of such energy resources.

To sum up, there are at least two obligations concerning the present generation that emanate from the intergenerational aspects of nuclear power production. Firstly, there is the duty not to jeopardize the safety and security of those living in the future or to violate their vital interests. Secondly, there is the duty to sustain future wellbeing, assuming that the availability of resources is able to guarantee that. ${ }^{3}$ The next section provides a detailed discussion on these two duties. It further unfolds the notion of prima facie duties before then going on to present the two temporal duties cited as prima facie duties. In Section 3, I shall examine the extent of the moral stringency of these duties in cases of internal conflict when it becomes impossible to comply with both duties at the same time.

\section{Moral Pluralism and Temporal Prima Facie Duties}

Pluralists believe that morality cannot be captured in one single principle or value in the way that that is done with monist views such as utilitarianism. Situations in which a plurality of morally relevant features should be taken into consideration are conceivable; the question of how to act then depends on which of these moral features is more compelling, and that in turn depends upon the situation context. In order to facilitate this distinction, William David Ross (1930/2002, 19-21) presents "prima facie duties" as duties that one has moral reason to follow in a certain situation. Such duties hold as long as they are not overridden by any more morally compelling duties. Our actual duty (or "duty proper" as Ross terms it) is then an allthings-considered duty in which moral conflicts have been properly addressed. Ross $(1930 / 2002,20)$ distinguishes between seven basic prima facie duties, including the duties of justice, beneficence, and non-maleficence.

"The phrase "prima facie duty' must be apologized for," Ross states, as it "suggests that one is speaking only of an appearance which a moral situation presents at first sight, and which may turn out to be illusory" (Ross 1930/2002, 20).

\footnotetext{
${ }^{3}$ In this paper, I am following a duty-based approach to intergenerational justice. A related question is whether these duties should be grounded in corresponding rights of future generations. In this paper, I take the liberty of not discussing this issue in detail; I just want to make two remarks. Firstly, I believe that the fact that future interest is susceptible to our action is enough reason to defend moral obligations towards them, without any reference to future rights. Secondly, even though "equal rights" is one of the main principles of fundamental equality, together with Barry, I think that this principle does not have any direct intergenerational application (Barry 1999). For more information on the issue of the rights of future generations, please consult (Gosseries 2008a).
} 
Nevertheless, Ross sticks to this notion as he believes that there is no better alternative. The phrase prima facie duty serves to highlight the fact that such duties might sometimes be overridden by more morally compelling duties. The latter does not, however, downplay their moral relevance: "these prima facie duties are features that give us genuine (not merely apparent) moral reasons to do certain actions." 4 The distinction between prima facie duty and actual duty is "best interpreted as being a distinction between a duty-imposing reason and a duty" (Wellman 1995, 249). In my interpretation of prima facie duties, I also emphasize that there are genuine grounds for duties (or legitimate duty-imposing reasons) but that says nothing about their moral stringency; this issue will be elaborated on in the next section.

Like moral pluralists, I consider it unfeasible to capture all morally relevant features in one single principle or value. I furthermore consider Ross's notion of our prima facie duty to relate to our temporal relationship with our descendants before then going on to formulate the specific duties that emanate from this relationship. ${ }^{5}$ The two duties presented in this paper do, to some extent, resemble certain basic Rossian duties. For instance, handing down resources to future generations could be a derivative of Ross's duty of justice or beneficence while not jeopardizing future people's vital interest can be subsumed under his duty of non-maleficence. However, unlike Ross (1930/2002, 29-30) who asserts that the basic (or fundamental) prima facie duties should be taken for granted as "mathematical axioms" or seen as "part of the fundamental nature of the universe," I derive these duties from the intergenerational nature of nuclear power production and consumption.

\subsection{The Prima Facie Duty Not to Harm Future People}

Following Barry's principle of vital interest to the effect that "the vital interests of people in the future have the same priority as the vital interests of people in the present" (Barry 1999, 97-99), I present the obligation not to negatively influence the vital interests of future generations by safeguarding their safety and security. This can alternatively be termed the obligation "not to harm" posterity. There is something that has to be said about the origins and the applications of this principle. One of the fundamental ethical obligations underscoring all human interaction is that of avoiding harm to others. In social interaction between people, for instance, it has been argued that an individual is sovereign as long as he is not harming another individual (Mill 1859/1998: 14). This no harm principle is also a leading creed for health care professionals; the related maxim that is frequently invoked in health care is thus: "to do no harm above all else" (Beauchamp and Childress 2009: Ch. 5). In environmental policy making, too, this principle is becoming increasingly influential, for instance, where it inspires the Precautionary Principle: namely "[w]hen an activity raises threats of harm to the environment or human health,

\footnotetext{
${ }^{4}$ The quote is from the introduction of a later reprint of the book "The Right and the Good" written by Phillip Stratton-Lake (Ross 1930/2002, xxxiv).

${ }^{5}$ Shrader-Frechette $(1994,1991)$ also refers to temporal prima facie duties in "Risk and Rationality" and later in "Equity and Nuclear Waste Disposal." However, it seems that this is an allusion to the literal or common sense meaning of this phrase (indicating at first sight or apparent) rather than to the Rossian interpretation of this notion.
} 
precautionary measures should be taken even if some cause and effect relationships are not fully established scientifically", as stipulated in the Wingspread Statement. ${ }^{6}$

What is particularly interesting about the precautionary principle is that it shifts the burden of proof; so, we should refrain from an activity (e.g., developing or applying a technology) unless there is enough evidence that it will not cause severe harm (Jonas 1984). Critics argue that this principle sets the bar so high that it could hamper technological innovation, but the question of where to set the bar is a matter of how to interpret the precautionary principle in the face of uncertainty. The precautionary principle has, above all else, "a purposeful role in guiding future political and regulatory action" (O'Riordan and Cameron 1994, 16). The no harm duty as advocated here resembles the precautionary principle in that it urges us to refrain from action whenever our actions might result in harm being inflicted upon future generations. So, in this interpretation, we would not guarantee future generations' "equal opportunity"; rather, we should refrain from action if such action could endanger posterity's "equal opportunity."

Before turning to discussing the moral stringency of the presented duties, let me first address two relevant questions with respect to this "no harm principle": i.e., (1) what exactly constitutes harm? and (2) how does this account of harm relate to Barry's vital interest? In the relevant literature, there is a general consensus that present generations should not harm future generations, and if it is unequivocally evident that an activity will harm future generations, then the ethical assertion that we should refrain from such an activity is rather simple and straightforward. ${ }^{7}$ In the case of nuclear waste, however, it is not about imposing direct harm, it is rather about the risk of harming people in the future. Indeed, it is inherently included in the definition of risk (as undesired effect times probability) that we can never completely exclude it, which is why I present this temporal no harm duty notion as a prima facie duty rather than an absolute duty. My notion of the temporal no harm duty should be read as a duty-imposing reason that urges us to decrease the possibility of causing harm to future generations.

The second question is about the relationship between Barry's vital interest principle and the one that I am defending here. Barry $(1999,105)$ argues that taking equal opportunity seriously means that "the condition must be such as to sustain a range of possible conceptions of the good life"; such a good life will in any case include "adequate nutrition, clean drinking-water, clothing and housing, health care and education." Here, my understanding of vital interest is in a very specific sense. I argued earlier in this paper that whenever we are in a position to negatively influence future opportunities, we should be careful not to narrow these opportunities. One

\footnotetext{
${ }^{6}$ This refers to an influential definition of the precautionary principle, presented by the Science and Environmental Health Network (1998).

${ }^{7}$ There are several objections that could be made to the notion of not harming future generation, the most well-known one being Derek Parfit's "non-identity" problem, to the effect that we cannot be said to harm future generations whose contingent identities rely on the actions and choices of contemporary people (Parfit 1984, Ch. 16). Here, I take the liberty of not discussing this or other general objections to the notion of obligations to future generations such as whether we should discount future well-being and future health impacts. For a detailed discussion of these objections, see (Taebi 2010, Sec. 1.3.). In this paper, I am merely stating that the creation of the intergenerational problem by the present generation (in the wake of nuclear power generation and consumption) gives rise to certain prima facie duties to future generations, the extent of which will be further examined here.
} 
clear way in which we can negatively affect future interest is by inappropriately disposing of nuclear waste. In my "no harm" account, what is considered to be of vital interest relates to the issues of safety and security. That is where the potential endangering lies if nuclear waste is inappropriately disposed of.

To summarize, moral agents have a prima facie duty not to inflict upon future generations the risk of harm if such risk could possibly culminate in violating the vital interests of future generations and could thereby endanger their equal opportunity. As far as the nuclear discussion is concerned, there is a general consensus that we should not impose "undue burdens" on future generations (IAEA 1995). Many nations agree that this undue burden clause should be taken to mean that nuclear waste should be disposed of in geological repositories which are believed to guarantee the long-term safety of future generations (NEA-OECD 1995). I will defer further discussion on this issue to Section 5.

\subsection{The Prima Facie Duty to Sustain Future Well-Being}

The second obligation relates to the appropriate consumption of nonreplicable resources or to what is known as intergenerational resourcism. Brian Barry (1989a: 515) states that "[f]rom a temporal perspective, no one generation has a better or worse claim than any other to enjoy the earth's resources." It would, however, be irrational to expect the present generation to leave all nonrenewable resources to its successors. For one thing, such restriction would seriously affect current well-being, which would inevitably affect future well-being as well. Another thing is that such a ban would not only include the present generations but also future generations and would therefore be beneficial to no one (Gosseries 2001, 344). As replicating such resources is not an option either, Barry $(1989 a, 519)$ argues that we need to offer compensation or recompense for depleted resources "in the sense that later generations should be no worse off [...] than they would have been without depletion." In this paper, I adopt Barry's reasoning regarding the adequate consumption of nonrenewable resources: "[t]he minimal claim of equal opportunity is an equal claim on the earth's natural resources" (Barry 1989b, 490). If we assume that welfare and well-being ${ }^{8}$ rely heavily on the availability of energy resources - a claim that could be historically underpinned by considering developments from the time of the industrial revolution until the present day-I would argue that we should compensate for a reduction in the opportunities for well-being as they can be brought about by energy resources.

The question that then arises is that of why we should leave the same amount of goods (or resources) for our descendants. Wilfred Beckerman $(1999,73)$ argues that taking the present levels of well-being as a point of comparison is arbitrary and has no normative significance when it comes to supporting intergenerational duty; "past generations seem to have survived with far less." Barry (1999: 106), on the other hand, states that "unless people in the future can be held responsible for the situation that they find themselves in, they should not be worse off than we are." To elaborate

\footnotetext{
${ }^{8}$ My interpretation of welfare is not necessarily or exclusively a monetary one, and to a great extent, it overlaps the interpretation linked to well-being. In this paper, I do not therefore distinguish between these two notions.
} 
on Barry's reasoning, I would argue that we, the present generation, have a prima facie duty to compensate future generations for the nonrenewable resources we have depleted (uranium). In this paper, I am not focusing on the question of how much we should compensate; my claim is merely that future generations should at least have access to equivalent resources that we have had access to and which necessitate some kind of compensation. ${ }^{9}$ In Section 4, I will explore the technological possibilities of offering compensation within the boundaries of the nuclear option.

\section{The Moral Stringency of Temporal Duties: Internal Conflict}

So far, two temporal duties have been formulated for the present generation in terms of prima facie duties, with the caveat that in possible conflicting situations, they could be overridden by more compelling duties. To comply with these duties, we need to implement certain technologies; two types of conflict could occur. In the first place, there could be internal conflict in situations where a certain technology does not allow us to accomplish both duties simultaneously; which duty should then be given priority? The second type of conflict that might occur is intergenerational conflict; the application of new technologies could shift the burden and benefit balance for present and future generations. Situations would then become thinkable in which we would need to impose more burdens on present generations in order to honor our duties to posterity, all of which raise the question of whether our temporal prima facie duties could be viewed as decisive when they conflict with the other duties we have to present generations. This section only explores internal conflicts; the discussion relating to intergenerational conflict is deferred to Section 5.

Internal conflict occurs when we cannot comply with both duties simultaneously. The question which then follows is: are we more duty-bound to consider other people's well-being or do we have a greater duty not to harm them or to at least decrease the likelihood of harm? In more philosophical terms, one can question whether the positive duty to secure benefits for posterity is in principle more morally compelling than the negative duty not to harm posterity. This has, in fact, given rise to a long-lasting debate among contemporary philosophers. In proposing his fundamental prima facie duties, David Ross $(1930 / 2002,21)$ distinguished between the two duties of beneficence and non-maleficence, even though he admits that "to injure others is incidentally to fail to do them good." He makes this distinction because he ascribes more stringent stipulations to the duty of non-maleficence than

\footnotetext{
${ }^{9}$ Barry (1989a) introduces the notion of "productive potential," arguing that depletion makes future generations worse off in terms of the productive potential that needs to be compensated. My notion of compensation as presented here is a rather simpler one, namely, that we should guarantee that future generations have access to equivalent resources. This notion poses several philosophical challenges, including how to determine what constitutes "equivalent" when we deplete one resource and seek to substitute it with another. We furthermore need to assume that we can "substitute critical natural resources with human-made resources" (Skagen Ekeli 2004, 434). At a more fundamental level, we need to assume that the substitutability of natural capital with man-made and physical capital is a fact (Pearce et al. 1989, 40-43). This assumption has many implications, such as the fact that man-made capital is, by definition, less diverse. This assumption also raises certain questions such as that of whether exhaustible energy resources should be compensated by technological progress or with renewable resources (Pearce and Turner 1990). More will be said about this issue in Section 3.
} 
to beneficence. John Rawls furthermore emphasizes that negative duties that require us not to cause harm carry more weight when compared with the positive duty to do something good for others (Rawls 1971, 98). ${ }^{10}$

The scholars Martin Golding and Daniel Callahan added a temporal dimension to this discussion. While Golding $(1981,62)$ conceives of a temporal duty by stating that we should produce and promote "conditions of good living for future generations," Callahan $(1981,78)$ emphasizes the duty "to refrain from doing things which might be harmful to future generations." These two positions differ mainly in the way that they relate to future generations; Golding defends a positive duty to benefit close future generations, while Callahan's negative duty extends much further into the future to contemplate the possibility of harm caused to remote future generations. The political philosopher Avner de-Shalit $(1995,13)$ merges these two positions; he emphasizes that contemporaries have a strong positive obligation to close and immediate future generations to "supply them with goods, especially those goods that we believe [...] will be necessary to cope with the challenges of life", but he also advocates less strong negative duties towards the distant future. ${ }^{11}$

We could distinguish between our two duties in terms of the types of goods protected by claiming that the no harm duty has to do with protecting the vital interests linked to the safety and security issues that exposure to radiation will bring. Similarly, the duty to sustain well-being relates to energy resources in the form of goods that could be used to safeguard well-being; we might therefore call them nonvital interests. If we accept this distinction, then the conclusion that in an internal conflict situation the no harm duty has a stronger moral appeal would seem straightforward enough. We have more compelling moral reasons to protect vital rather than non-vital interests. Let us now evaluate whether the distinction presented between the two duties is as clear-cut as has been indicated here; any overlap or interdependency might affect their moral stringency. One can, for instance, argue that if future generations are to enjoy their equal opportunity for well-being, their health and safety first need to be guaranteed. In other words, in order to be able to enjoy the fruits of the resources at their disposal, future generations must first be protected against ionizing radiations (one assumes that also in the future, being exposed to ionizing radiation will lead to serious health problems). ${ }^{12}$ It is indeed true that the no harm duty is a fundamental prerequisite attached to the duty to sustain welfare, but the scope of the no harm duty is much broader. Endangering the safety and health of people of the future would be wrong, regardless of the duty to sustain well-being. What is so innately morally wrong is the fact that future people whose safety and security are conceivably compromised by exposure to radiation would never be able to enjoy "equal opportunity." Hence, the distinction in terms of the types of good these duties protect will still apply.

Conversely, we can argue that not complying with the duty of sustaining wellbeing could be viewed as harmful. In other words, without a safe and affordable energy supply, many basic needs such as medical care will inevitably be

\footnotetext{
${ }^{10}$ Beauchamp and Childress (2009, Ch. 4) also discuss the distinction between the notions of beneficence and non-maleficence.

${ }^{11}$ De-Shalit defends a "communitarian" approach to intergenerational justice; see (De-Shalit 1995).

${ }^{12}$ I owe these suggestions to an anonymous reviewer.
} 
compromised, all of which could then harm future generations. It is indeed true that well-being inherently entails certain health issues. However, even when we accept that "sustaining well-being" involves the negative duty of "not imposing harm" by virtue of the positive duty of safeguarding energy resources, this does not affect the moral decisiveness of the two duties in relation to each other. Another important distinction we should make between the two duties pertains to the time periods (and thus to the number of generations) to which they relate. The duty to sustain wellbeing has been presented as a positive duty relating to the time span during which we could affect the lives of close future generations by influencing the availability of energy resources. However, our knowledge about future energy provision is very limited. Let me illustrate this with an example. There are now 440 nuclear power reactors operational worldwide, and an estimation made in 2010 forecasts that in due course, some 500 new reactors will be built (WNA 2010). These estimations that stem from before the Fukushima accident could turn out to be unreliable, but let us assume - for the sake of argument - that such predictions will be borne out. Even then, our ability to positively affect the well-being of people on the basis of the availability of the necessary energy resources will hardly extend to a hundred years. ${ }^{13}$ Beyond that period, it is very difficult or, more to the point, virtually impossible to foresee what the energy landscape will look like, let alone to positively affect it. On the other hand, the "no harm duty" as presented here will have a time span of thousands of years, the duration for which nuclear waste is radiotoxic and potentially harmful. Hence, if we cannot comply with both duties simultaneously, the no harm duty will become morally more compelling because of the type of goods it is protecting and because of the time span and the number of generations it involves.

Another important issue when assessing the moral stringency of the two duties in relation to each other is the fact that the duty of sustaining well-being and the ensuing notion of compensation rest on the serious assumption that nuclear power deployment will continue. While one can argue that depleting nonrenewable resources creates the obligation to compensate future generations, further justification is needed to demonstrate that such compensation lies within the boundaries of the nuclear option. One can argue that the availability of other suitable energy resources should counteract the depletion of uranium as a nonrenewable resource and that solar and wind energy should, for instance, be promoted (Pearce and Turner 1990). Nevertheless, the focus of this paper is upon the boundaries of nuclear technology. There are certain features of nuclear technology that are alien to other nonrenewable resources (such as fossil fuel) and so that could, to some extent, justify exploring the possibility of compensation within the confines of this technology. One possible way of compensating is, for instance, by making energy production methods more efficient and that, too, would contribute to making the remaining stock of nonrenewable resources go further (Barry 1989a, 519-520). Unlike oil, gas, or coal, we can deploy nuclear fuel substantially more efficiently by recycling and reusing the waste. Furthermore, there are nuclear production methods

\footnotetext{
${ }^{13}$ Here, I am assuming that it will take several decades to build these reactors and that they will remain operational for several decades
} 
that produce more fuel than they consume; more will be said about such options in the next section.

One important aspect of this type of compensation relates to the available reserves of natural uranium. The availability of uranium is usually taken to refer to its geological certainty and to production costs. According to recent estimations, there will be at least enough reasonably priced uranium available for approximately 100 years when using only existing conventional reactors. If we include estimations of all the available resources (i.e., phosphate deposits and seawater (SER 2008)), the period of uranium availability will extend to thousands of years (IAEA-NEA 2008). A related issue that could also justify compensation within the boundaries of nuclear technology involves looking to the alternative, to thorium, that is naturally more abundant than uranium. From the very early days of nuclear fission deployment, thorium has been seen as a serious alternative (Kazimi 2003). Indeed, starting up thorium fuel cycles has certain negative implications, a key one of which is that during production, a ready-made material will be produced that is deployable for the manufacture of nuclear bombs (WNA 2008).

In conclusion, if we assume that nuclear power production will continue, we can say that the technologies that should then be preferred should be those that keep more resource options open to future generations. Whether future generations will ultimately deploy the available nuclear resources is something that we cannot and perhaps should not even want to decide for them; we merely provide them with the opportunity to do so. ${ }^{14}$ There is, however, no doubt that long-term compensation in terms of extending nuclear fuel is sound if, and only if, we assume that nuclear fission (i.e., the current nuclear power production method) will continue for a long period of time. The latter downgrades the moral importance of this notion of compensation within the boundaries of nuclear technology as defended here, especially when the two duties cannot be complied with simultaneously.

To recapitulate, the argument given in this section is that-all things being equal - the prima facie duty not to impose harm on future generations is more morally compelling than the duty to sustain well-being by regulating energy resources. This should not, however, be interpreted in absolute terms because the ranking of moral relevance (or the determining of the actual duty as Ross terms it) requires us to consider all prima facie duties and address their potential conflicts. Imagine, for instance, a situation in which the harm is relatively minor compared to the possible benefits; we can conveniently argue that the obligation of beneficence would then take precedence over that of nonmaleficence. $^{15}$

\footnotetext{
${ }^{14}$ A related question is that of whether we can guarantee that future generations will acquire the same level of well-being from these resources. Like Barry, I argue that the latter will fall beyond the scope of the principle of responsibility. "What is important from the point of view of justice is the range of choices open to [future generations], rather than what they get out of it" (Barry 1983, 20).

${ }^{15}$ Such situations are, for instance, conceivable in biomedical ethics; see (Beauchamp and Childress 2009, Ch. 5).
} 


\section{Nuclear Energy: A Review of the Technology and Its Future}

Technology plays a crucial role in establishing how to comply with these duties. With nuclear power production, compensation for the depleting reserves of uranium could be provided in different ways. First of all, minor adjustments can be made to make the existing production methods more efficient or to extract more uranium from other natural resources such as see water (SER 2008). The focus in this paper is, however, on the entire fuel cycle. In the following paragraphs, I will discuss two existing and two future fuel cycles, and I shall evaluate how they score from the point of view of complying with our temporal prima facie duties.

Any nuclear fuel cycle consists of several major steps, including the mining and milling of uranium ore, its enrichment, fuel fabrication, irradiation in a reactor, and the optional waste treatment methods employed after irradiation and before the final disposal of the waste. Uranium is currently deployed in most operational energy reactors, which are commonly referred to as light water reactors (LWR). Naturally occurring uranium contains different constituents (isotopes) in the form of the minor fissile isotope that is capable of producing energy in existing reactors but is present in less than $1 \%$ of natural uranium and the major isotope $(>99 \%)$ that is not fissile and therefore not deployable in existing operational reactors. In the following paragraphs, I shall distinguish between the two existing fuel cycles (open and closed) while simultaneously presenting two future fuel cycles that will help us to comply better with the presented prima facie duties towards future generations. ${ }^{16}$

(1) The Open Fuel Cycle: In an open or once-through fuel cycle (of the type common in the US and certain other countries like Sweden), enriched uranium is irradiated once. The material remaining after irradiation is known as spent fuel and contains not yet irradiated uranium and plutonium together with other radionuclides, all of which have to be disposed of as waste. The waste in an open fuel cycle should ideally be isolated from the biosphere for about 200,000 years; this period is referred to as the waste lifetime.

(2) The Closed Fuel Cycle: An alternative option is to reprocess (recycle) spent fuel so that deployable materials (uranium and plutonium) are extracted in order to afterwards be reused as fuel; the reinserting of these materials closes the cycle, which is why this method is dubbed the closed fuel cycle method. The waste lifetime of the remaining waste is about 10,000 years. Closed fuel cycles are common in many European countries, but certain other countries, like Japan, that have access to fewer natural resources primarily see it as a way of extending their energy resources. Reprocessing and reusing deployable material considerably increase the long-term availability of uranium (IAEANEA 2008). The closed fuel cycle scores better in the fulfilling of both duties as it decreases the waste lifetime while increasing the availability of resources. In the first three rows of Table 1, an internal comparison of these two fuel cycles is presented; the plus signs in the closed fuel cycle column indicate its better score in terms of fulfilling the stated duties when compared to the open

\footnotetext{
${ }^{16}$ This is maybe not the right place to elaborate on these fuel cycles at length. For a profound and technically detailed discussion of these fuel cycles, the reader is referred to the following pages (Taebi and Kloosterman 2008, 181-184) and (Taebi and Kadak 2010, 1347-1352).
} 
Table 1 Four fuel cycles and their relative scores with respect to temporal duties

Not to impose harm

To sustain well-being

Closed fuel cycle

Partitioning and transmutation

The breeder fuel cycle

fuel cycle. The next two fuel cycles are proposed to explore how far we could go - technologically speaking - in fulfilling these duties. These fuel cycles are scientifically proven, but years of development and industrialization will be required before they can be made operational.

(3) Partitioning and Transmutation: In addition to reprocessing, a further deactivating of the remaining waste can be achieved by means of a new method known as Partitioning and Transmutation (P\&T). This involves separating and dividing (partitioning) the materials remaining after reprocessing so that they can afterwards be eliminated (transmuted) in Fast Reactors; ${ }^{17}$ these reactors can irradiate the radionuclides that the currently operational LWR cannot irradiate. This can substantially reduce the waste lifetime to several hundred years (NRC 1996). It is thus a fuel cycle that scores relatively better on the no harm duty scoreboard, as is indicated in Table 1 .

(4) The Breeder Fuel Cycle: Fast reactors could also be deployed in the configuration of a nuclear breeder for the purposes of making (or breeding) more fuel than is consumed during operation. The best feasible option is to irradiate the abundant uranium isotope (which cannot be irradiated in a LWR) and breed a certain plutonium isotope, which can be extracted by reprocessing, before then reusing it as fuel. In this way, uranium consumption will become substantially more efficient; the two plus signs given in Table 1 indicate that fulfilling the second duty is what is best for this particular fuel cycle. This fuel cycle is designed to enhance the resource durability, and the remaining waste contains very long-lived radionuclides; therefore, it does not score well on the no harm duty.

As can be seen, different fuel cycles are capable of complying with the temporal duties in different ways. I would again like to emphasize that the plus and minus signs in Table 1 merely signify relative comparisons between these four fuel cycles. Before assessing the desirability of these technologies from the point of view of safeguarding the interests of future generations, we should also remind ourselves of how they shift the burdens and benefits for contemporaries.

\footnotetext{
${ }^{17}$ It is important to note that there are currently only a few fast reactors in use. Before this fuel cycle can become an industrial reality, a considerable number of additional reactors must first be built. See for more information (Taebi and Kadak 2010, Sec. 4.3.).
} 


\section{Intergenerational Conflicts and Three Challenges}

So far, I have argued that we have two temporal duties with regard to posterity. These duties are presented as prima facie duties in an effort to address any possible conflict existing between these duties. In Section 3, an internal conflict was discussed. We concluded that in an all-things-being-equal situation, the no harm duty should take precedence over the duty to sustain future well-being. If we now take the no harm duty as the leading notion when choosing a fuel cycle, then maximally reducing the long-term concerns for future generations through P\&T would seem to be the most desirable option, as can also be seen in Table 1. Let us dwell for a moment on how the implementation of this fuel cycle affects the interest of contemporaries.

As stated in Section 4, the P\&T fuel cycle should be viewed as a complementary strategy to the existing closed fuel cycle. In other words, before the successful reprocessing and extraction of uranium and plutonium from spent fuel take place, it is impossible to continue eliminating the remaining radionuclides through P\&T. So, let us first explore how reprocessing shifts the burdens and benefits for the present generation before then continuing with the matter of P\&T.

Reprocessing is a chemical process employed for the separation of uranium and plutonium; it is a process that creates considerable safety, security, and economic burdens for the present generation. To be precise, it necessitates more nuclear activity than usual, and the chemical radiotoxic residual of reprocessing subsequently has to be disposed of as well. ${ }^{18}$ In nuclear technology, one distinguishes between safety and security in order to emphasize the distinction between unintentional and intentional harm. In this case, safety is connected with the unintentional release of radiotoxic material that can subsequently lead to health problems. Security, on the other hand, refers to the intentional releasing of radioactive substances; both as a result of sabotage and in the form of proliferation pertaining to the manufacturing and disseminating of nuclear weapons (IAEA 2007). Reprocessing creates additional proliferation risk for contemporaries if one considers that plutonium separated during reprocessing could also be used for destructive purposes. Indeed, such separating is primarily undertaken for civil purposes (to produce nuclear fuel and to reinsert it in the cycle), but security concerns will certainly mount during this process and will remain until the separated plutonium is again deployed in a nuclear reactor. ${ }^{19}$ Furthermore, since reprocessing plants are quite expensive, only a few countries have them at their disposal. In Europe, where a majority of the countries tend to favor the closed fuel cycle approach, there are currently two operational reprocessing plants located in Great Britain and in France.

One could illustrate the additional burdens for contemporaries by contemplating the general situation and the recent accident in Japan. As a country with no substantial energy resources of its own, Japan is particularly keen to make efficient

\footnotetext{
18 Together with Jan Leen Kloosterman, I have discussed these arguments at some length elsewhere (Taebi and Kloosterman, 2008).

${ }^{19}$ Strictly speaking, the separated plutonium from a nuclear reactor is not weapon-grade or equivalent to the type of material that is usually used to manufacture nuclear weapons. This plutonium does, however, have some serious destructive capacities; for a detailed technical discussion on this matter, see (Taebi Forthcoming).
} 
use of the resources it has at its disposal. It is therefore understandable that Japan has opted for closed fuel cycles and reprocessing so that the spent fuel can be reused. Since the country does not yet have a reprocessing plant of its own, Japanese waste is reprocessed in France and in the UK; Japan is currently building its own reprocessing plant. Apart from the additional safety and security burdens brought by transporting spent fuel and reprocessed waste back and forth, using separated plutonium as a fuel creates additional risks too. Since the nuclear accident in Fukushima Daiichi, Reactor 3 has been giving serious cause for concern. It is the presence of plutonium as a mixed oxide fuel (MOX) in this reactor's fuel that is giving rise to such grave concerns; $\mathrm{MOX}$ is a mixture of uranium and reprocessed plutonium. Since, if inhaled, plutonium is extremely toxic, its potential release into the environment is reason enough for serious concern (Cooper et al. 2003, 113).

The next important issue is that P\&T is merely a technology that has been scientifically proven at lab level. It still requires decades of development which, in turn, will necessitate serious investments in this technology (NEA-OECD 2002). On top of the burdens of reprocessing, these other burdens also have to be borne by contemporaries or at least by those nations that are capable of developing the technology. ${ }^{20}$ To conclude, the burdens of developing and eventually deploying P\&T will mainly be borne by the present and immediately following generation, while it is primarily designed to reduce safety burdens for remote future generations. ${ }^{21}$

At least three objections could be made to the idea of accepting additional burdens for contemporaries in order to reduce the likelihood of causing harm to remote future generations. The first has to do with the long-term safety that geological repositories supposedly guarantee so that there is no need to further deactivate the waste. A second rejoinder to this view is the contention that placing additional safety and security burdens upon contemporaries is highly undesirable and therefore unjustified. The last objection relates to the distribution of these additional burdens between contemporaries.

\subsection{Repositories Guarantee Long-Term Safety; Why Should We Accept More Current Burdens?}

Some people argue that current technology is perfectly capable of handling the waste problem. We should avoid "undue burdens" on future generations (IAEA 2009), and that can best be achieved - so the argument goes - in deep geological repositories. As a matter of fact, this solution enjoys broad consensus among nuclear energyproducing countries. The Nuclear Energy Agency (NEA-OECD 1999, 11) articulates this consensus as follows: "Potential host geologic formations are chosen for their long-term stability, their ability to accommodate the waste disposal facility, and also their ability to prevent or severely attenuate any eventual release of radioactivity. This natural safety barrier is complemented and augmented by an engineered system

\footnotetext{
${ }^{20}$ Due to the inherent technological implications and complexity, not all countries will be capable of developing or deploying this technology; see (IAEA 2004).

${ }^{21}$ The intergenerational distribution of the burdens and benefits of different fuel cycles is more precisely and extensively discussed in a joint paper written with Andrew Kadak. We have mapped out the consequences of four possible fuel cycles in terms of the moral values at stake. Both Partitioning and Transmutation and the Breeder Fuel Cycle are discussed there (Taebi and Kadak 2010).
} 
designed to provide primary physical and chemical containment of the waste." Many countries are currently taking the first steps towards realizing such repositories; some countries such as Finland, France, Sweden, Spain, and the United Kingdom have already set up operational repositories for less radiotoxic types of waste, for intermediate-level and low-level wastes (NEA-OECD 1996). Some countries like Finland have already chosen their repository sites for high-level waste, and Sweden has narrowed down its attention to two possible sites (Rogers 2009).

In view of these considerations, it seems unjustifiable to impose more risks on the present generation simply in order to reduce the waste lifetime. However, one of the problems with long-term waste disposal is the inherent uncertainty both in terms of technical predictions and regarding future societies. There is enough historical evidence to underpin the notion that we are hardly in a position to anticipate human behavior and the status of future societies a few hundred years from now, let alone 10,000 or 100,000 years on. The question that naturally follows from this is whether this should have a bearing on our moral responsibility towards future generations. Kristian Skagen Ekeli argues that our ignorance with respect to future generations "reduces our responsibility in a temporal dimension because in most areas it is impossible to foresee the interests and resource needs of future generations" (Skagen Ekeli 2004, 442); this corresponds to the way in which Martin Golding (1981, 70) views our duties to future generation as he argues "the more distant the generation we focus upon, the less likely it is that we have an obligation to promote its good." Skagen Ekeli $(2004,442)$ argues, on the other hand, that there are things that we could be certain about such as the physiological needs of future people and that it is therefore immoral to impose risks upon future generations that threaten these physiological needs when risk assessment is presented that is "supported by scientifically based harm scenarios." Even though Skagen Ekeli acknowledges the difficulties that arise from scientific disagreement about harm scenarios, he does not consider this to be an insurmountable problem. Unlike Skagen Ekeli, I argue that in addressing the acceptability of a certain technology with long-term consequences, all the uncertainties and the ensuing problem of disagreement on predictions do pose intractable challenges. This is particularly the case in the foreseeing of the long-term consequences of geological repositories.

A second relevant aspect is how to deal with possible uncertainties regarding the technical predictions for the remote future in policy making. Let me illustrate this by giving the example of how such uncertainty was anticipated in the case of the Yucca Mountain's repositories once allocated for the permanent disposal of American spent fuel for a million years. The Yucca Mountain site in the State of Nevada was proposed some decades ago, but it met with strong public resistance. During the most recent presidential election, Barak Obama promised Nevadans that he would stop further development of this site if he were elected, and it was a promise that he kept. Even though the Yucca Mountain's repository idea has officially been abandoned, it is worth considering how its radiation protection standards for longterm protection have been set.

At the same time as acknowledging the difficulties surrounding the long-term uncertainties of technical systems, it has been proposed that we should distinguish between different future people: "a repository must provide reasonable protection and security for the very far future, but this may not necessarily be at levels deemed 
protective (and controllable) for the current or succeeding generations" (EPA 2005, 49036). People living in the next 10,000 years deserve a level of protection equal to the current level, and the generations belonging to the period extending beyond 10,000 years could be exposed to a much higher radiation limit. The underlying argument for this distinction is sought in the low degree of predictability for the remote future and the fact that any positive influence on such societies is meaningless, all of which is believed to diminish our responsibility towards future generations. $^{22}$

We could now ask whether this also releases us from the duty of not imposing possible harm on future generations. An ensuing question might be to ask whether the present generation has a duty to reduce the waste lifetime to more conceivable time periods in order to avoid ending up in a situation in which - from a pragmatic point of view - we need to discriminate against remote future generations which, in turn, increases the possibility of harming people living in the remote future. Elsewhere, I argue that the distinction between future generations lacks solid moral justification, concluding that in the light of long-term uncertainties, we should reconsider whether geological repositories really are the best option for final waste disposal (Taebi Forthcoming).

\subsection{Should We Impose More Safety and Security Burdens on Contemporaries?}

The next objection I discuss relates to the justifiability of additional burdens for contemporaries. As argued above, developing and deploying P\&T to reduce any future burdens linked to nuclear waste bring with it serious additional economic, safety, and security burdens for the present generation. In this paper, I will leave the issue of whether it is justifiable for this generation to bear the economic burdens unanalyzed. Instead, I will focus on the morally more important question of whether the additional safety and security risks are justified. Let us just remind ourselves that more nuclear activities are involved in P\&T and that during reprocessing, separated plutonium (in an initial step towards P\&T) involves high proliferation risks. If it is indeed true that a nuclear accident or nuclear warfare could have consequences that would be suffered far beyond the present generation, some people - such as Axel Gosseries (2008b) — argue that we should avoid risks of malevolent use, particularly from the intergenerational justice point of view, by defending geological disposal as the fastest and best feasible option for the disposal of waste in the near future.

It is widely accepted that since the present generation has created the waste, it should also - as far as possible — bear the responsibility of managing it (NEA-OECD 1995, 9). Quite how the latter point should be interpreted is, however, open to debate. Some argue that since the benefits of nuclear power are mainly enjoyed by the present generation, they should also be the ones to bear the burdens. A general consensus in nuclear waste management is the principle of equality between generations, meaning that similar levels of protection for people living now and in the future should be guaranteed (NEA-OECD 1984); geological repositories are

\footnotetext{
${ }^{22}$ The notion of diminishing responsibility over the course of time - as referred to here - is defended by the Swedish KASAM (2005, Ch. 9) and the American National Academy of Public Administration (NAPA 1997).
} 
believed to best comply with this principle. However, as emerged from the American example, designing such an underground disposal repository amounts to a violation of the equality principle.

I would even go one step further by arguing that the rationale of the equal treatment argument is faulty. The equal treatment principle presupposes that there is an equal temporal distribution of benefits that should justify an equal distribution of the burdens. A utilitarian would argue that nuclear power production serves the higher good of the well-being of mankind so that everyone is better off, even those who belong to future generations. Even if - for a while-we take this argument for granted, we can assert that the temporal distribution of benefit is not properly incorporated into this line of reasoning. The current benefits are unquestionably greater than the benefits for those who will be alive 100,000 years hence; this could justify placing a higher burden on the present generation in order to establish a fair distribution of burdens and benefits. So, the default situation should be that the present generation remains responsible for the waste problem. If one then decides to transfer parts of this risk to the future and if this necessitates putting remote future generations at a disadvantage, then "the burden of proof is on the person who wishes to discriminate," as Shrader-Frechette $(2002,97)$ rightly stated. ${ }^{23}$

It is, however, quite reasonable to consider ways of reducing the burdens upon the present generation, particularly the security burdens. After all, the additional proliferation risks are the main reasons why countries like the USA have decided to avoid reprocessing. In the first place, it is the significant quantities of highly enriched uranium and weapon-grade plutonium emanating from dismantled warheads in the wake of the Cold War that need to be taken care of. As proliferation is a significant problem associated with reprocessing (and with the possible further deactivating of waste through advanced fuel cycles such as P\&T), serious attempts have been made to avoid this problem. Proliferation-resistant technologies have been proposed so that we can enjoy the benefits of reprocessing by, for instance, reducing the waste volume and its waste lifetime; one of the serious alternatives worth mentioning is the Global Nuclear Energy Partnership, alternatively known as GNEP (Pilat 2006).

\subsection{Who in the Present Generation Should Bear the Burden?}

The last objection that will be explored here is that of how the additional safety and security burdens will be distributed between contemporaries and whether that should be seen as relevant when addressing the intergenerational conflicts. Some scholars argue that people who are disadvantaged in terms of income, education, or occupation generally bear greater environmental and health risks; see for instance Bullard (1994) and Bullard and Johnson (2000). Issues concerning the distribution of burdens and benefits between contemporaries are known as intragenerational justice or alternatively environmental justice. ${ }^{24}$

\footnotetext{
${ }^{23}$ Shrader-Frechette disagrees with the claim that nuclear electricity benefits future persons and presents two objections to this idea; see for more information (Shrader-Frechette 2002, 97-8).

${ }^{24}$ Some scholars - such as Shrader-Frechette (2002, Ch. 5) - see the temporal inequality that arises from the case of geological disposal of nuclear waste as an instance of environmental injustice. In this paper, I distinguish between spatial and temporal justice by stressing that the former refers to environmental justice and the latter to intergenerational justice.
} 
If we now accept these arguments by acknowledging that the least well-off in society are indeed exposed to higher environmental risks and if we go on to conclude that the latter violates the norms of distributive justice-as for instance argued by Wigley and Shrader-Frechette (1996) in the case of a uranium enrichment facility in Louisiana - then the question of whether the extending of these activities is justified seems legitimate. To put it bluntly, can we justify increasing the injustice among contemporaries and disadvantaging the least well-off in present-day society in order to reduce the possibility of harming remote future generations? This casts serious doubt on the extent of the moral legitimacy of the prima facie duty of not harming future generations. ${ }^{25}$ This reasoning is however dubious as it assumes that current injustice should continue. We can argue that if there is a problem surrounding the distribution of burdens and benefits among contemporaries, we need to address and solve this problem irrespective of any additional activity.

One might further argue that the dilemma presented is a false dilemma because the choice should not be between injustice done to the present generation and injustice towards the future as a result of nuclear power deployment. Perhaps, it is rather the case that we should avoid nuclear power and choose instead other energy provision systems. Even though such an argument seems at first glance defensible, I shall refrain from getting involved in such a discussion here. Addressing the social desirability of nuclear power production is indeed a very legitimate discussion; however, in this paper, I have confined the analysis to different options for the production of nuclear power in order to enable an internal comparison to be made between different methods. In other words, before being able to compare nuclear energy with other energy sources, it is advisable to be clear about the type of nuclear energy (or fuel cycle) one has in mind and to appropriately address the spatial and temporal distribution of burdens and benefits.

\section{Conclusions and Recommendations}

In this paper, I have considered the morally desirable option for nuclear power production. In other words, assuming that we continue using nuclear energy, I have questioned which technology we should deploy for its production. As nuclear power production predominantly produces present benefits and carries deferred costs for future generations and as we are in a temporally good position to visit costs on future generations, I argue that the desirable option should be primarily formulated in terms of the duties that present generations have towards posterity (1) not to jeopardize future generations' vital interests, something alternatively known as the no harm duty and (2) to sustain future well-being insofar as that can be achieved with the natural resources available. Fulfilling these duties brings with it the implementation of certain technologies, all of which shifts the burdens and benefits for different generations. The question, as correctly formulated by Brian Barry $(1999,94)$, then

\footnotetext{
${ }^{25}$ See also in this connection Okrent $(1999,878)$ who states that there is an inherent conflict between intergenerational and intragenerational equity: "[ $\mathrm{t}]$ he millions of dollars spent today to save a relatively few statistical lives thousands of years in the future could save many more lives during the current generations."
} 
becomes, if "we could provide a benefit or avoid a loss to people in the future at some cost to ourselves, are we morally required to do so?"

In order to be able to answer this question and address these intergenerational conflicts, I treated temporal duties as prima facie duties (or simply duty-imposing reasons), alluding to the fact that they might be overruled by morally more important duties. I argued that - in all-things-being-equal situations - the duty not to harm future generations will be morally more compelling because of the type of goods being protected (i.e., the vital interests) and because of the time span and the number of generations involved. This supports the introduction of Partitioning and Transmutation (P\&T) fuel cycles in order to substantially reduce waste lifetime periods. Such a fuel cycle creates additional safety, security, and economic burdens for contemporaries; these intergenerational conflicts were further explored.

Three objections were raised to the additional burdens that emanate from P\&T. The first objection related to the possibility of disposing of the waste in geological repositories, thus supposedly guaranteeing long-term safety. It was however shown-as in the American example - that before we can design repositories, we need to violate the equality principle with regard to remote future generations. The second objection questions the legitimacy of these additional burdens for contemporaries. This reasoning errs, however, as it shifts the burdens of proof. Assuming that the present generation has predominantly benefited from nuclear power, the default situation should then be that this generation remains primarily responsible for dealing with it; it is therefore the transferring of these risks to remote future generations, thus putting them at a disadvantage that requires justification. Indeed, there is every reason to reduce the burdens upon contemporaries, especially proliferation risks as the consequences of an accident or nuclear warfare would extend far beyond the present generation. Technological solutions could be presented to such issues. The third objection relates to the distribution of additional burdens among contemporaries. If one assumes that the least well-off in society are generally exposed to higher safety and health risks, one could argue that increasing such environmental injustice by applying P\&T would be highly undesirable. Even though this argument mistakenly presupposes that current injustice should continue, it emphasizes the necessity of addressing the intragenerational justice issue. To conclude, the morally desirable option in terms of nuclear power production is primarily seen here as that which safeguards the interests of future generations, after which we should explore how the latter shift the burdens and benefits for contemporaries before deciding whether the option chosen is sufficiently justified.

Since the introduction of atomic power for peaceful purposes half a century ago, its deployment has engendered much public and political controversy. It is to be expected that the recent nuclear accidents in Fukushima Daiichi in Japan will, more than ever before, bring the debate to the forefront of controversy. Even though I started this paper by circumventing the general desirability debate, it is worth just stopping to consider what this analysis can potentially contribute to that particular highly relevant public and political discourse. When reflecting on the desirable energy mix, one needs to consider nuclear energy in relation to other energy sources; the moral insight provided could help one distinguish between different fuel cycles, all of which can facilitate a comparison between a certain nuclear fuel cycle and another specific energy system. A similar analysis to the one I have given in this 
paper could be presented in order to include other nonrenewable energy systems such as fossil fuels. Such analysis could help us to establish the desirable energy mix in line with the notion of distributive justice which accounts for both spatial and temporal burdens - benefit distribution between generations. The ensuing question would then be: how can we balance the duties owed to present generations with those owed to posterity? (Okrent 1999; Hillerbrand and Ghil 2008) There is at least one fundamental philosophical question that deserves serious attention in this respect and that is the problem of the incommensurability of burdens and benefits. In other words, before we can assess the desirable energy mix, we must first find a unified way to, perhaps qualitatively, compare and balance the intrinsically different burdens and benefits that emanate from nuclear power production and other energy systems, both in spatial and temporal dimensions.

Acknowledgments Earlier drafts of this paper were presented at the IEEE International Symposium on Technology and Society, which was held in Tempe (Arizona) in May 2009 (Taebi 2009) and at the Biennial Conference of the Society for Philosophy and Technology (SPT) in Enschede (the Netherlands) in July 2009. In addition to thanking the audiences at these conferences, I wish to thank Ibo van de Poel, Stephan Gardiner, and two anonymous reviewers for their useful comments. The usual disclaimer with regard to authorial responsibility applies.

Open Access This article is distributed under the terms of the Creative Commons Attribution Noncommercial License which permits any noncommercial use, distribution, and reproduction in any medium, provided the original author(s) and source are credited.

\section{References}

Arneson, R. J. (1989). Equality and equal opportunity for welfare. Philosophical Studies, 56(1), 77-93.

Athanasiou, T., \& Baer, P. (2002). Dead heat: global justice and global warming. New York: Seven Stories Press.

Barry, B. (1978). Circumstances of justice and future generations. In B. Barry \& I. Sikora (Eds.), Obligations to future generations (pp. 204-248). Philadelphia: Temple University Press.

Barry, B. (1983). Intergenerational justice in energy policy. In D. MacLean \& P. G. Brown (Eds.), Energy and the future (pp. 166-179). Totowa: Rowman and Littlefield.

Barry, B. (1989a). The ethics of resource depletion. In Democracy, power and justice, essays in political theory (pp. 511-525). Oxford: Clarendon.

Barry, B. (1989b). Justice as reciprocity. In Democracy, power and justice, essays in political theory (pp. 463-494). Oxford: Clarendon Press.

Barry, B. (1999). Sustainability and intergenerational justice. In A. Dobson (Ed.), Fairness and futurity: essays on environmental sustainability and social justice (pp. 93-117). New York: Oxford University Press.

Beauchamp, T. L., \& Childress, J. F. (2009). Principles of biomedical ethics (6th ed.). New York: Oxford University Press.

Beckerman, W. (1999). Sustainable development and our obligations to future generations. In A. Dobson (Ed.), Fairness and futurity: essays on environmental sustainability and social justice (pp. 71-92). New York: Oxford University Press.

Bullard, R. D. (1994). Unequal protection: environmental justice and communities of color. San Francisco: Sierra Club Book.

Bullard, R. D., \& Johnson, G. S. (2000). Environmental justice: grassroots activism and its impact on public policy decision making. Journal of Social Issues, 56(3), 555-578.

Callahan, D. (1981). What obligations do we have to future generations? In E. Partridge (Ed.), Responsibilities to future generations: environmental ethics (pp. 73-85). Buffalo: Prometheus Books.

Cooper, J. R., Sokhi, R. S., \& Randle, K. (2003). Radioactive releases in the environment: impact and assessment. West Sussex: Wiley. 
De-Shalit, A. (1995). Why posterity matters: environmental policies and future generations. London: Routledge.

EPA. (2005). Public health and environmental radiation protection standards for Yucca Mountain. 40 CFR Part 197, Part II. Washington D.C.: Office of Radiation and Indoor Air U.S. Environmental Protection Agency.

Gardiner, S. (2001). The real tragedy of the commons. Philosophy and Public Affairs, 30(4), 387-416.

Gardiner, S. (2003). The pure intergenerational problem. The Monist, 86(3), 481-501.

Gardiner, S. (2006). A perfect moral storm: climate change, intergenerational ethics and the problem of moral corruption. Environmental Values, 15(3), 397-413.

Golding, M. P. (1981). Obligation to future generations. In E. Partridge (Ed.), Responsibilities to future generations: environmental ethics (pp. 61-72). Buffalo: Prometheus Books.

Gosseries, A. (2001). What do we owe the next generation(s)? Loyola of Los Angeles Law Review, 35(1), 293-354.

Gosseries, A. (2008a). On future generations' future rights. Journal of Political Philosophy, 16(4), 446474.

Gosseries, A. (2008b). Radiological protection and intergenerational justice. In G. Eggermont \& B. Feltz (Eds.), Ethics and radiological protection (pp. 167-195). Louvain-la-Neuve: Academia-Bruylant.

Hillerbrand, R., \& Ghil, M. (2008). Anthropogenic climate change: scientific uncertainties and moral dilemmas. Physica D: Nonlinear Phenomena, 237(14-17), 2132-2138.

IAEA. (1995). The principles of radioactive waste management. Radioactive waste safety standards programme. Vienna: IAEA.

IAEA. (2004). Technical implications of partitioning and transmutation in radioactive waste management. Vienna: IAEA.

IAEA. (2007). IAEA safety glossary, terminology used in nuclear safety and radiation protection. Vienna: IAEA.

IAEA. (2009). Common user considerations (CUC) by developing countries for future nuclear energy systems: report of stage no. 1. Vienna: IAEA.

IAEA-NEA. (2008). Uranium 2007: resources, production and demand. A joint report by the OECD Nuclear Energy Agency and the International Atomic and Energy Agency. Paris: IAEA and NEA-OECD.

Jonas, H. (1984). The imperative of responsibility: in search of an ethics for the technological age. Chicago: University of Chicago Press.

KASAM (2005). Nuclear waste state-of-the-art reports 2004. In S. Norrby, M. Stenmark, C. R. Brakenhielm, H. Condé, T. L. Andersson, \& R. Sandström (Eds.). Stockholm: National Council for Nuclear Waste (KASAM), Sweden

Kazimi, M. (2003). Thorium fuel for nuclear energy. American Scientist, 91(5), 408-415.

Meyer, L. H., \& Roser, D. (2006). Distributive justice and climate change the allocation of emission rights. Analyse \& Kritik, 28, 241-267.

Mill, J. S. (1859/1998). On liberty. In J. Gray (Ed.), On liberty and other essays (pp. 1-128). New York: Oxford University Press.

NAPA. (1997). Deciding for the future: Balancing risks, costs, and benefits fairly across generations. A report for the U.S. Department of Energy. Washington D.C.: National Academy of Public Administration.

NEA-OECD. (1984). Long-term radiation protection objectives for radioactive waste disposal, report of a group of experts jointly sponsored by the Radioactive Waste Management Committee and the Committee on Radiation Protection and Public Health. Paris: Nuclear Energy Agency, Organisation for Economic Co-operation and Development.

NEA-OECD. (1995). The environmental and ethical basis of geological disposal of long-lived radioactive wastes: a collective opinion of the Radioactive Waste Management Committee of the Nuclear Energy Agency. Paris: Nuclear Energy Agency, Organisation for Economic Co-operation and Development.

NEA-OECD. (1996). Radioactive waste management in perspective. Paris: Nuclear Energy Agency, Organisation for Economic Co-operation and Development.

NEA-OECD. (1999). Progress towards geologic disposal of radioactive waste: where do we stand? An international assessment. Paris: Nuclear Energy Agency, Organisation for Economic Co-operation and Development.

NEA-OECD. (2002). Accelerator-driven systems (ADS) and fast reactors (FR) in advanced nuclear fuel cycles: a comparative study. Paris: Nuclear Energy Agency, Organisation for Economic Co-operation and Development.

NRC. (1996). Nuclear wastes: technologies for separations and transmutation. Washington, DC: Committee on Separations Technology and Transmutation Systems, Board on Radioactive Waste Management, National Research Council (NRC). 
O’Riordan, T., \& Cameron, J. (1994). The history and contemporary significance of the precautionary principle. In T. O’Riordan \& J. Cameron (Eds.), Interpreting the precautionary principle (pp. 12-30). London: Earthscan Publications.

Okrent, D. (1999). On intergenerational equity and its clash with intragenerational equity and on the need for policies to guide the regulation of disposal of wastes and other activities posing very long-term risks. Risk Analysis, 19(5), 877-901.

Page, E. (1999). Intergenerational justice and climate change. Political Studies, 47(1), 53-66.

Page, E. (2006). Climate change, justice and future generations. Cheltenham: Edward Elgar Publishing.

Parfit, D. (1984). Reasons and persons (1987th ed.). Oxford: Clarendon.

Pearce, D. W., \& Turner, R. K. (1990). Economics of natural resources and the environment. Baltimore: Johns Hopkins University Press.

Pearce, D. W., Markandya, A., \& Barbier, E. B. (1989). Blueprint for a green economy. London: Earthscan Publications.

Pilat, J. F. (2006). Nonproliferation and the Global Nuclear Energy Partnership (GNEP). Los Alamos National Laboratory (LA-UR-06-7674).

Rawls, J. (1971). A theory of justice, revised edition (1999th ed.). Cambridge: The Belknap Press of Harvard University Press.

Rogers, K. A. (2009). Fire in the hole: a review of national spent nuclear fuel disposal policy. Progress in Nuclear Energy, 51(2), 281-289.

Ross, W. D. (1930/2002). The right and the good. Oxford: Clarendon Press.

Science and Environmental Health Network. (1998). Wingspread statement on the precautionary principle. Ames: Science and Environmental Health Network.

Sen, A. (1982). Equality of What? In A. Sen (Ed.), Choice, welfare and measurement (pp. 353-369). Oxford: Oxford University Press.

SER. (2008). Nuclear energy and sustainable energy provision-advisory report. The Hague: SER (The Social and Economic Council in the Netherlands).

Shrader-Frechette, K. (1991). Risk and rationality. Philosophical foundations for populist reforms. Berkeley: University of California Press.

Shrader-Frechette, K. (1994). Equity and nuclear waste disposal. Journal of Agricultural and Environmental Ethics, 7(2), 133-156.

Shrader-Frechette, K. (2002). Environmental justice: creating equality, reclaiming democracy. Oxford: Oxford University Press.

Shue, H. (1999). Global environment and international inequality. International Affairs, 75, 531-545.

Shue, H. (2003). Climate change. In D. Jamieson (Ed.), A companion to environmental philosophy (pp. 449-459). Malden: Blackwell.

Skagen Ekeli, K. (2004). Environmental risks, uncertainty and intergenerational ethics. Environmental Values, 13(4), 421-448.

Taebi, B. (2009). nuclear power and prima facie duties towards future people. Paper presented at the ISTAS IEEE International Symposium on Technology and Society Proceedings 2009, Tempe (Arizona)

Taebi, B. (2010). nuclear power and justice between generations. A moral analysis of fuel cycles $(\mathrm{PhD}$ Dissertation) (Vol. V, Simon Stevin Series in the Ethics of Technology). Delft: Delft University of Technology.

Taebi, B. (Forthcoming). Intergenerational risks of nuclear energy. In S. Roeser, R. Hillerbrand, M. Peterson, \& P. Sandin (Eds.), Handbook of risk theory. Dordrecht: Springer.

Taebi, B., \& Kadak, A. C. (2010). Intergenerational considerations affecting the future of nuclear power: equity as a framework for assessing fuel cycles. Risk Analysis, 30(9), 1341-1362.

Taebi, B., \& Kloosterman, J. L. (2008). To recycle or not to recycle? An intergenerational approach to nuclear fuel cycles. Science and Engineering Ethics, 14(2), 177-200.

Wellman, C. (1995). Real rights. New York: Oxford University Press.

Wigley, D. C., \& Shrader-Frechette, K. (1996). Environmental justice: a Louisiana case study. Journal of Agricultural and Environmental Ethics, 9(1), 61-82.

WNA (2008). Thorium, Information paper. http://www.world-nuclear.org/info/inf62.html. Accessed 1 March 2011.

WNA (2010). World Nuclear Power Reactors \& Uranium Requirements 2010, Information Paper (1 November 2010). http://www.world-nuclear.org/info/reactors.html. Accessed 1 November 2010. 